\title{
BACTERIAL AND CLINICAL ASSESSMENT OF TWO DIFFERENT DESIGNS TOOTH SUPPORTED OVERDENTURE
}

\author{
Nora Sheta* and Mai Adel Helmy**
}

\begin{abstract}
This study compared the bacteriological effect and clinical finding of two different designs of abutments in tooth supported over denture.

Materials and Methods: Twenty male completely edentulous patients were selected and randomly divided into two equal groups according to the abutments design. Group 1: Patients were rehabilitated with complete over denture supported by two dome shaped endodontically treated teeth with composite plug. And Group 2: Patients were rehabilitated with complete over denture supported by two dome shaped Endodontically treated teeth with zirconium post and coping. The Microbiological swabs were collected from buccal, lingual, mesial and distal surfaces of the abutment for each patient in order to evaluate the bacterial colonization. On other hand, the clinical assessment was done including pocket depth evaluation. at the time of insertion, 3, 6, 9 and 12 months after over denture insertion. The data were collected and statistically analyzed. Results: The quantitative bacterial culture from each group of patients $(n=10)$ had revealed statistical significant increase the percentage of bacterial count in (group I) of patients that were wearing over dentures without coping compared to the other group of patients (group II) that were wearing over dentures with zirconium coping with statistical significant difference $(\mathrm{p}<.0 .001<.0 .001)$ and regarding the clinical assessment there was no statistical significant difference between two groups .

Conclusion: Abutments supported over denture with zirconium copings as regard to bacterial and clinical assessment are much better for oral hygiene maintenance than abutments without copings. Further studies are recommended by other experimental means like Electron Microscopy, other bacterial species to support this research.
\end{abstract}

KEY WORDS: Overdenture; Coping materials; microbiological.

* Assistant, Professor Removable Prosthodontics Department, faculty of dentistry, Cairo University.

** Lecture, Removable Prosthodontics Department, faculty of dentistry, Cairo University. 


\section{INTRODUCTION}

Over dentures are removable prosthesis placed over prepared abutment teeth, roots or implants and have an acceptable durability and serviceability When placed over natural teeth, the teeth provide good stability for the over dentures and provide the proprioception sensation by action of the periodontal ligament. This also provides support for the over dentures and minimize the rate of residual alveolar ridge Resorption ${ }^{(1-3)}$, thus preventing the need for denture adhesives. The advantage of the over dentures over than complete dentures not only minimize the soreness of bearing tissues and improve the denture stability but also increases the masticatory efficiency, comfort and patient satisfaction. ${ }^{(4,5)}$

The human oral cavity is colonized by more than 500 species of bacteria at 108-109 bacteria per milligram of dental plaque. Microscopic examination of early plaque formation on teeth showed that the pioneer bacteria is started colonization to the salivary pellicle on teeth as well as on dental materials within minutes after tooth cleaning. Initial colonizing bacteria appears along cracks and pits in the enamel, These early colonizers are mostly streptococcoci, contribute to plaque development and ultimately to oral diseases. Investigations of dental plaque concluded there is distinct difference between the composition of supragingival (Gram-positive cocci) and subgingival plaque (Gram-negative anaerobic bacilli). Various researches of oral bacteria adhesion have been reported for different materials including Titanium, Cobalt chromium, resins and ceramics. ${ }^{(6-9)}$

Bacterial cells are considered as major components of biofilm formation, a solid surface, and a fluid medium. Biofilm formation occurs on all hard surfaces, e.g. the tooth surface, restorative materials and implant components. There are four stages appear in the formation of a biofilm to a non-shedding surface : Stage 1: Conditioning layer formation called pellicle which consists of numerous components including phosphoproteins, prolinerich proteins, glycoproteins histidine-rich proteins, enzymes, and other molecules that can function as receptors for bacteria. Stage 2: Transport of bacteria to the substrate surface in which the initial transport of microbes to the substrate may occur. Stage 3: Bacterial adhesion in which the bacterial surface structure form bridges between the conditioning layer and the bacteria , stage4:bacterial colonization and biofilm maturation will take place in this stage in addition to firmly attached microorganisms to the tooth surface .11,12)

Zirconia is the popular name for Zirconium dioxide $(\mathrm{ZrO} 2)$, was discovered by $\mathrm{M}$. H. Klaproth (German chemist) in1789. However, it was introduced into the field of dentistry since a few years ago. It has become one of the best choices due to its superior properties ${ }^{(13) .}$ The phenomenon of transformation toughening of zirconia results in extraordinary bending and tensile strength, extremely high compact strength, in addition to its fracture and chemical resistance. For this reason, zirconium has been reported to have 'self-repairing' properties thus stopping crack propagation ${ }^{(14)}$.

Many researchers reported that the excellent biocompatibility and aesthetic properties as well as the high mechanical strength of the zirconia with a compression resistance of about $2000 \mathrm{MPa}$ has been reported when compared to traditional metals . zirconia has been introduced to the clinical practice in order to it is favorable light dynamic , high fracture toughness and high resistance to wear and fracture by fatigue loading. All of these advantages in addition to its low attraction to plaque accumulation have made zirconia one of the best choice materials of particular interest. To date only inadequate number of clinical studies evaluated the zirconia as a coping under the over dentures. ${ }^{(15-17)}$

Recent improvement in the field of computer aided designing (CAD) and computer aided 
manufacturing (CAM) offered easier manipulation of different materials of high quality, especially ceramics ${ }^{(\mathbf{1 8}-20)}$.

The aim of the present study was to assessed the clinical outcome of zirconia coping supported complete over denture on two natural abutments regarding clinical attachment level and microbiological evaluation.

\section{MATERIAL AND METHODS}

Twenty male patients their ages ranged between 50-65 years were selected from out -patient clinic of the Prosthodontics department. Faculty of Dentistry , Cairo University. They were completely edentulous patients with remaining canines that used as abutment for the tooth support over denture and opposing conventional complete dentures were constructed.

All patients were free from any systemic diseases or any abnormal habits such as clenching, bruxism and drug abuse.

Upon the clinical examination all the edentulous ridges were covered with firm, healthy mucosa free from any severe bony undercut and with adequate inter arch distance. all cases with poor oral hygiene were excluded .The canines were free from periodontal and Periapical lesions and no dental plaque was visible .

Face bow record and mounting the diagnostic casts for tentative jaw relation record was done to insure sufficient inter-arch space for the copings, the denture base and artificial teeth .No history of antibiotic within two months before taking microbiological specimens and No history of using bacterial disinfection before taking microbiological specimens.

Primary upper and lower impression using irreversible hydrocolloid impression material with suitable stock tray size was done and intentional root canal treatment were done for all the remaining canines abutment teeth .
The patients were divided randomly after canines root canal treatment into two equal groups $(n=10)$ :

Group I: Patients were rehabilitated with complete over denture supported by two dome shaped tooth preparation with composite plug.

Group II: Patients were rehabilitated with complete over denture supported by two dome shaped zirconium coping with post extend into the root canal preparation.

The clinical crown of each canine was reduced 2-3 $\mathrm{mm}$ above the free gingival margin, taking place labially and lingually until dome-shaped. The crest of the dome shape was placed over the long axis of the abutment, and the sharp line angles were rounded.

Group I : Filling the root canal orifice by composite plug was done, then finishing and polishing of the composite was take place as usual.

Group II: A chamfer finishing line was placed supragingivally and root canal preparation was done using rotary instrument and gates size 2, 3 and 4 was used to flaring the walls of root canal were prepared carefully to remove all the undercuts and create post hole space preparation was done using the standard procedures with rotary instruments *Penetration drill of Unimetric set, Dentsply, Switzerland

Lubricate the root canal was done lightly with a periodontal probe and petroleum jelly** Relience Dental Manufacturing Co. USA

Plastic readymade post was used and apply on it the duralay*** Relience Dental Manufacturing Co. USA to take the root canal impression after complete setting of the duralay the easily reinsertion and removal of the duralay post was checked, build up the coping around the dome shaped abutment was . done

Finishing the coping around the dome 
shaped abutment was take place by finishing stone in order to be adapted the .coping around the abutment margins

All over pick up impression with poly-

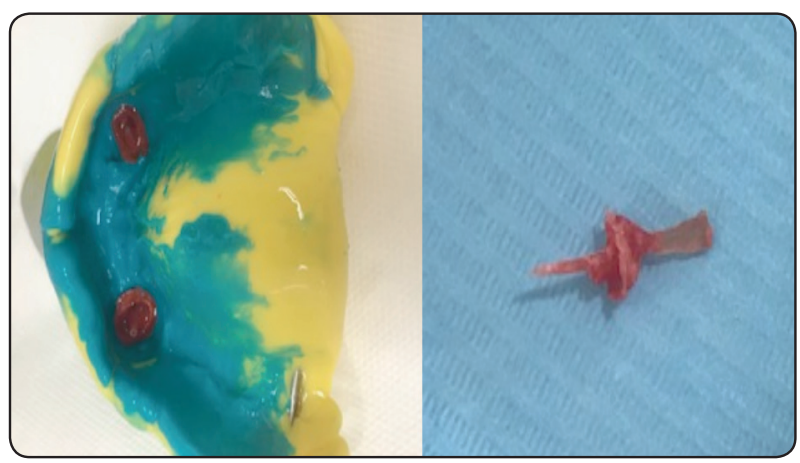

Fig. (1) A. secondary pick up impression. B. Plastic readymade post with duralay applied on it.

vinyl siloxane elastomeric impression material (Heavy and light body) was taken. Silicon impression material, thixoflex M, Zhermach Clinical, Italy (Figure (1

A Ceramic milling machine was used to convert the post to zirconium post and coping as the computer numeric control (CNC) data were transmitted to a milling machine* Wieland dental, ivoclar vivodent,

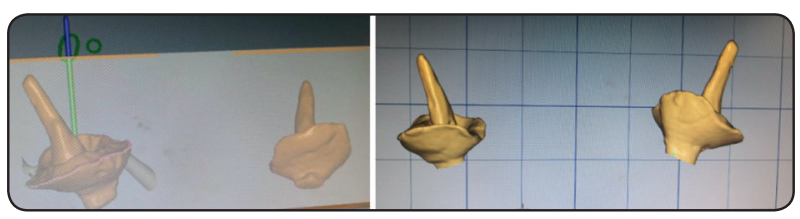

Fig. (2):CAD system to mill the coping.

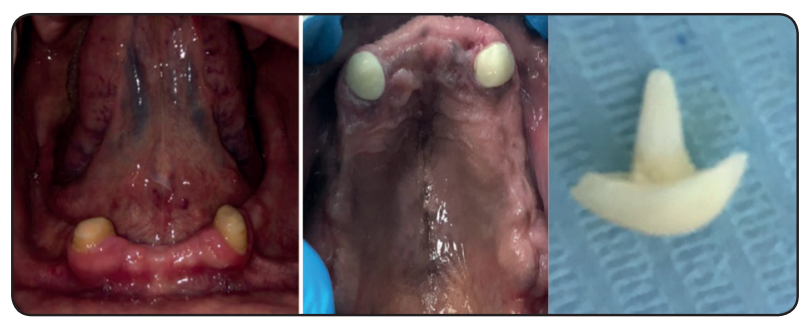

Fig. (3) A. Dome shaped abutment preparation ,B. Cemented zirconium coping, C. zirconium post and coping .
Zenotic select hybrid ,Germany connected to the CAD system to mill the coping from semi-sintered zirconia blanks Zenostar MO 2 Figure (2)

Cementation the coping with resin ce(ment was done. Figure(3

Mounting the upper cast to semi adjustable articulator was done by using max.illary face bow

The jaw relations were recorded by check bite technique and teeth arrange.ment was done

The artificial teeth were arranged for balanced occlusion and the waxed up trial dentures were evaluated intraorally for phonetics, aesthetics ,retention , stability, and patient satisfaction. The trial dentures were processed into heat cured acrylic resin, finished, and pol. ished as usual

At delivery, The occlusal interferences were refined on the articulator after clinical remount

Clinical remounting was done in order to refine the occlusal interferences and justify the occlusion. . Final adjustment was done intra-orally by selective .grinding

The pressure indicting paste was applied to the fitting surface of the over . denture to check pressure areas

Instructions for proper denture hygiene were stressed upon then ,the patients were recalled for post insertion care and further need for adjustment

\section{Clinical evaluation :}

Attachment loss was measured from the gingival margin to the cementoenamel junction (CEJ). Clinical attachment loss (CAL) refers to the measurement of the loss of the position of the soft tissue in 


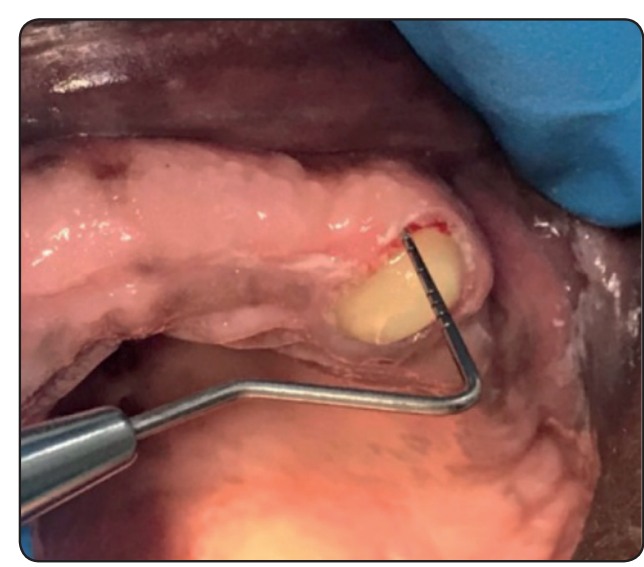

Fig. (4) Pocket depth evaluation .

relation to the CEJ, which is a fixed point that does not change throughout life.

Clinical attachment loss was assessed by both the probing using graduated periodontal probe (Williams Probe). Pocket depth was evaluated at the time of insertion then 3,6 and 9 months after denture delivery . Figure(4)

\section{Bacterial evaluation :}

Microbiological evaluation, the bacterial changes were evaluated at time of delivery and after 1 month. The samples were collected in the morning hours between 10-12 O'clock giving chance for the patients to use the dentures several hours before taking the swabs. No history of antibiotic or bacterial disinfectants use was recorded within two months before taking the microbiological specimens and patients were instructed not to eat any food before taking the swabs.

The gingiva around zirconia coping and natural tooth were air dried and isolated before taking the swab.

Microbiological swabs were collected from buccal, lingual, mesial and distal canine surfaces by using sterile endodontic paper points Densply Dental,Tianjin which were gently inserted into the sulcular depth of the canines until feeling of resistance. then, the paper point was kept in place for few seconds .

The swabs were taken from each patient in the following intervals: - First swab, at denture insertion. - Second swab, one week later - Third swab, two weeks later. - Fourth swab, three weeks later - Fifth swab, four weeks later

Each swab was inoculated immediately in a sterile tube containing $1 \mathrm{ml}$ sterile saline. For each sample three sterile dilutions were done to obtain sample dilutions of $10^{-1}, 10^{-2}$, and $10^{-3}$, taking 50 micron liter (using micro pipette) from each dilution

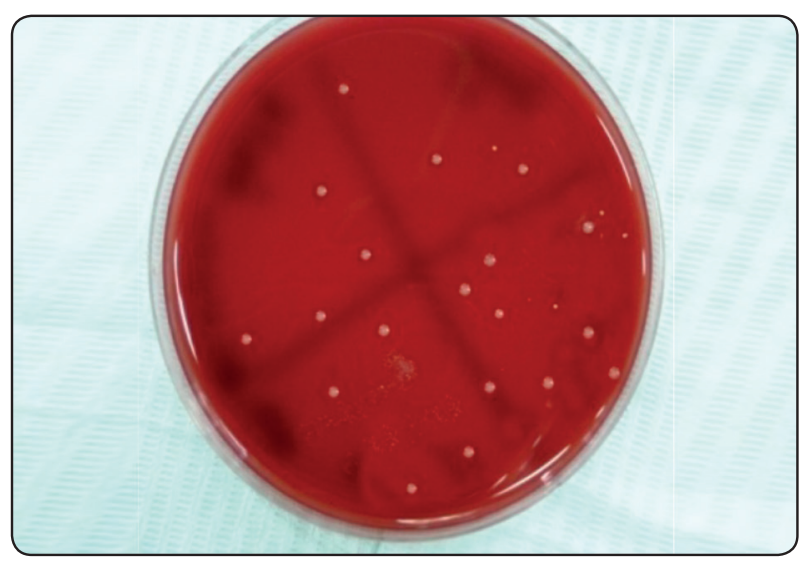

Fig. (5) Bacterial culture on blood agar

were plated onto blood agar plate, sample was then spread using a sterile glass rod then incubated at $37^{\circ} \mathrm{c}$ for 24 hours not more than 48 hours.

\section{Quantitative assessment:}

Visible colonies of each organism were counted in every plate, and the number of colonies-plate was multiplied by the corresponding dilution factor and by 10 to determine the total colony forming units per $\mathrm{ml}$ of suspension. Figure (5)

\section{RESULTS}

One way analysis of variance (ANOVA) followed by Tukey's post hoc test for multiple comparisons was performed to calculate the significance between both sides . Independent sample-t test was used 
to compare between independent samples for parametric data. The significance level was set at $\mathrm{P} \leq 0.05$. Statistical analysis was performed with IBM $®$ SPSS $®$ Statistics Version 20 for Windows.

\section{Regarding the Attachment loss evaluation:}

This study showed that there was increase in measurement of pocket depth in group I than group II . but there were insignificant difference in pocket depth records between both groups natural dome shaped tooth without coping and zirconia coping at all-time intervals as P-value $>0.05$, as listed in table (1) and showed in Table (1).

TABLE(1): PD measurements of the two groups

\begin{tabular}{|c|c|c|c|c|c|}
\hline & \multicolumn{2}{|c|}{$\begin{array}{c}\text { Group I } \\
\text { (natural dome } \\
\text { shaped tooth } \\
\text { without coping) }\end{array}$} & \multicolumn{2}{c|}{$\begin{array}{c}\text { Group II } \\
\text { (zirconia } \\
\text { coping) }\end{array}$} & \multirow{2}{*}{$\begin{array}{c}\text { P } \\
\text { value }\end{array}$} \\
\cline { 2 - 5 } & $\mathrm{M}$ & $\mathrm{SD}$ & $\mathrm{M}$ & $\mathrm{SD}$ & \\
\hline Base line & 0.71 & 0.31 & 0.57 & 0.23 & $0.09 *$ \\
\hline 6 months & 0.89 & 0.38 & 0.66 & 0.1 & $0.06 *$ \\
\hline 12 months & 1.32 & 0.62 & 0.97 & 0.43 & $0.09 *$ \\
\hline 18 months & 1.76 & 0.76 & 1.23 & 0.66 & $0.1 *$ \\
\hline
\end{tabular}

M\%; Mean Percentage, SD; Standard deviation, P;

Probability Level *insignificant difference

Regarding the Microbiological evaluation

The quantitative bacterial culture from each group of patients $(n=10)$ as shown in table (2) had revealed higher percentage of bacterial count in group 1 of patients that wear over denture without copings compared to that of group 2 of zirconium copings with statistical significant difference $\mathrm{p}<.0 .001$ regarding bacterial colonization specially Streptococcus sangius strains.

Table (2): Colony forming unit (CFU) in the two groups

\begin{tabular}{|c|c|c|c|c|c|}
\hline \multirow{2}{*}{} & \multicolumn{2}{|c|}{ Group I } & \multicolumn{2}{c|}{ Group II } & \multirow{2}{*}{ P value } \\
\cline { 2 - 5 } & $\mathrm{M}$ & $\mathrm{SD}$ & $\mathrm{M}$ & $\mathrm{SD}$ & \\
\hline 1 weeks & 86.8 & 19.3 & 68.5 & 13.1 & $0.02 * *$ \\
\hline 2 weeks & 58.6 & 4.2 & 46.3 & 3.4 & $0.0001 * *$ \\
\hline 3 weeks & 52.8 & 5.6 & 25.5 & 5.8 & $0.0001 * *$ \\
\hline 4 weeks & 48.8 & 8.9 & 10.3 & 7.9 & $0.0001 * *$ \\
\hline
\end{tabular}

M; mean SD; Standard deviation P; Probability level **Significant difference

\section{Means and SDs of quantitative bacterial culture CFU/ml between groups}

Regarding bacterial colonization specially Streptococcus sangius strains with means (9 X10 $\left.{ }^{5} \pm 2.84 \mathrm{CFU} / \mathrm{ml}\right)$ for group I without coping and (2 X $10^{5} \pm 1.30 \mathrm{CFU} / \mathrm{ml}$ ) for group II zirconium copings There were statistical significant increase in group I than group II

\begin{tabular}{|c|c|c|c|}
\hline Group & M & SD & P value \\
\cline { 1 - 2 } Group I & $9 \times 10^{5}$ & 2.84 & \multirow{2}{*}{$0.0001 * *$} \\
\cline { 1 - 2 } Group II & $2 \times 10^{5}$ & 1.30 & \\
\hline
\end{tabular}

M; mean SD; Standard deviation P; Probability level **Significant difference

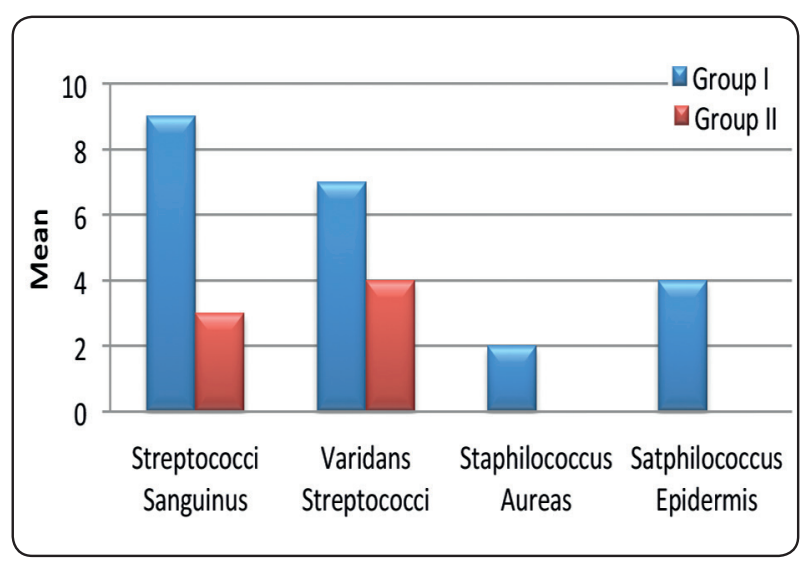

Fig. (6) Shows presence of microorganisms after paper points culture from both groups (Quantitative assessment study) 
The following histogram revealed presence of microorganisms related to the both groups at the four observational periods. After 1 week of over denture insertion, species of Streptococcus sanguinus and varidans Streptococci were identified in more higher level in group I than group II , there were also a lower numbers of bacterial species included two species of Staphilococcus aureus and Staphilococcus epidermis only appear in group I . Number of species remains mainly stable after 4 weeks of over denture use. Figure (6)

\section{DISCUSSION}

Plaque accumulation on tooth or coping surfaces induces an inflammatory reaction in the gingival and alveolar mucosa around teeth leading to periodontitis and subsequent both alveolar bone resorption and periodontal pocket formation . ${ }^{(21)}$ Pockets around remaining teeth are considered the main location for bacterial colonization specially under the overdenture prosthesis can be a source of the inflammation which lead to increase in pocket depth and end by loosening of the tooth and compromised the over denture support and stability ${ }^{(22,23)}$.

At the time of delivery, all patients received the same instructions regarding the use of the denture as they must remove the denture at night to give chance for oral tissues to recover.

Patients were also instructed to clean their dentures after each meal under running water, with no other chemical or mechanical means that might affect plaque accumulation and microbial flora.

The samples were taken nearly at the same time in the morning between 10-12 a.m. in order to fix the time of sample collection and before taking any kind of food to neglect the effect of meal on microbial flora. Also, The second, third and fourth swaps were taken on the intervals of two, three and four weeks after date of insertion, to give chance for denture adjustment and to make sure that the patients were comfortable in wearing the new denture. ${ }^{(24)}$
Regarding the microbial evaluation the Streptococcus sanguinus bacteria was chosen as it is the most earlier bacterial colonizer on both tooth surface and restorative materials ,also it can be easily isolated and identified by simple and low cost experimental tools. ${ }^{(25)}$

Furthermore, The excellent mechanical of the zirconia including low electrical and thermal conductivity, high resistance to the wear and decrease surface roughness can explain the minimize in account of bacterial adherent to the zirconium coping as compared to natural tooth dome shaped preparation .Also, number of studies have reported on the fabrication of zirconia copings for providing a successful alternative to classic gold copings, especially when the patient's esthetic demands are high. $^{(26,27)}$

Also, in this study the low plaque formation related to zirconia surface may be attribute to the other additional advantage of zirconia surface which is the maintenance of material texture with roughness lower than $0.2 \mu \mathrm{m}$ and low surface energy to avoid biofilm formation, especially in the proximal areas subjected to ceramic adjustment as it stabilize soft tissues against inflammation. ${ }^{(28,29)}$

In this study the results revealed that, after 12 weeks of overdenture use, no statistically significant difference was observed in loss of clinical attachment was detected,This conclusion is in conformity with the few studies that have assessed over dentures retained on natural abutments or implants using zirconium for fabrication of copings and/or implant abutments . ${ }^{(30-32)}$

\section{CONCLUSION}

Within the limitations of this study, it can be concluded that Zirconium copings as regard to its biological and bacterial adherence is much better for oral hygiene maintenance than natural dome shaped abutment. More recommended to increase follow up period in order to assess the pocket depth around abutments. 


\section{REFERENCES}

1. Kaira L.S, Mishra R.2013; Telescopic denture a treatment modalitity of preventive prosthodontics. International Journal of Oral Health Sciences I Jul-Dec, 3(2):121-124.

2. Petropoulos VC, Mante FK. 2011;Comparison of retention and strain energies of stud attachments for implant over dentures. J Prosthodont .20:286-93.

3. Mosby. Mosby's Dental Dictionary. $2^{\text {nd }}$ Ed. Mosby, Maryland Heights MI.2004; p. 64.

4. Galofré M., Palao D ., Vicario M., Nart J and Violant D. 2018; Clinical and microbiological evaluation of the effect of Lactobacillus reuteri in the treatment of mucositis and peri-implantitis: A triple-blind randomized clinical trial. J Periodontal Res. Jun; 53(3):378-390. doi: 10.1111/ jre.12523.

5. Kim Y, Oh TJ, Misch CE, Wang HL. Occlusal considerations in implant therapy: Clinical guidelines with biomechanical rationale. Clin Oral Implants Res 2005;16:26-35.

6. Subramani K, Jung RE, Molenberg A, Hammerle CH. 2009 ; Biofilmon dental implants: a review of the literature. Int J Oral Maxillofac Implants;24:616-626.

7. Hojo K, Nagaoka S, Ohshima T, Maeda N. 2009; Bacterial interactions in dental biofilm development. J Dent Res; 88:982-990.

8. Kriebel K, Hieke C, Müller-Hilke B, Nakata M and Kreikemeyer B .2018; Oral Biofilms from Symbiotic to Pathogenic Interactions and Associated Disease Connection of Periodontitis and Rheumatic Arthritis by Peptidylarginine Deiminase. Front. Microbiol. 9:53. doi: 10.3389/fmicb. 2018.00053

9. Filoche S, Wong L, Sissons CH. 2010; Oral biofilms: emerging concepts in microbial ecology. J Dent Res.; 89: 8-18.

10. Scarano A, Piattelli M, Caputi S, Favero GA, Piattelli A. 2004; Bacterial adhesion on commercially pure titanium and zirconium oxide disks: an in vivo human study. J Periodontol.; 75:292-6.

11. M. Shabzendedar, H. Moosavi, F. Kebriaee and A. Daneshvar-Mozafari.2011; The Effect of Topical Fluoride Therapy on Microleakage of Tooth Colored Restorations," Journal of Conservative Dentistry, Vol. 14, No. 3 , pp. 297-301.

12. S. M. Azevedo, K. Z. Kantorski, L. F. Valandro, M. A. Bottino and C.A. Pavanelli. 2012; Effect of Brushing with Con- ventional versus Whitening Dentifrices on Surface
Rough- ness and Biofilm Formation of Dental Ceramics, Ge- neral Dentistry, Vol. 60, No. 3, pp. 123-130.

13. Tosiriwatanapong T and Singhatanadgit W .2018;ZirconiaBased Biomaterials for Hard Tissue Reconstruction. Bone and Tissue Regeneration Insights, Vol. 9: 1-9

14. Zembic, A., Sailer, I., Jung, R.E. \& Hammerle, C.H. 2009; Randomized-controlled clinical trial of customized zirconia and titanium implant abutments for single-tooth implants in canine and posterior regions:3-year results. Clinical Oral Implants Research, 20: 802-808.

15. Rösch R, Mericske-Stern R.2008; Zirconia and removable partial dentures [in French and German]. Schweiz Monatsschr Zahnmed. 118:959-974.

16. Beuer F, Aggstaller H, Richter J, Edelhoff D, Gernet W. 2009; Influence of preparation angle on marginal and internal fit of CAD/CAM-fabricated zirconia crown copings. Quintessence Int. 40:243-250.

17. Zafiropoulos, Rebbe J, Thielen U, Deli G, Beaumont C, Hoffmann O 2010 ;Zirconia Removable Telescopic Dentures Retained on Teeth or Implants for Maxilla Rehabilitation. Three-Year Observation of Three Cases Gregory-George Journal of Oral Implantology , Vol. XXXVI (6): 455-465.

18. Abduo J, Lyons K, Swain M .2010; Fit of zirconia fixed partial denture: a systematic review. J Oral Rehabil. $37: 866-876$.

19. Beuer F, Schweiger J, Edelhoff D 2008; Digital dentistry: an overview of recent developments for CAD/CAM generated restorations. Br Dent J. 204:505-511.

20. Beuer F, Steff B, Naumann M, Sorensen JA 2008; Loadbearing capacity of all-ceramic three-unit fixed partial dentures with different computer-aided design (CAD)/ computer-aided manufacturing (CAM) fabricated framework materials. Eur J Oral Sci.116:381-386.

21. Coulthwaite L and Verran J. 2007;Potential Pathogenic Aspects of Denture Plaque. British Journal of Biomedical Science 64.4 : 180-189.

22. Harrison Z, Johnson A, Douglas WI. 2004; An in vitro study in to the effect of limited range denture cleansers on surface roughness and removal of Candida albicans from conventional heat - cured acrylic resin denture. J Oral Rehabl. 31: 460-467.

23. Hannig C, Hannig M. 2009; The oral cavity-a key system to understand substratum-dependent bioadhesion on solid surfaces in man. Clin Oral Investig. 13:123-139. 
24. Taha ED.2017 ; The Effect of Different Denture Base Materials on Microbial Flora Growth. Current Science International $: 6: 314-320$.

25. Lasserre JF, Brecx M C and Toma S. 2018; Oral Microbes, Biofilms and Their Role in Periodontal and Peri-Implant Diseases .Materials, 11, 1802

26. Hashim D, Cionca N, Courvoisier DS, Mombelli A.2016; A systematic review of the clinical survival of zirconia implants. Clin Oral Investig. 20:1403-1417.

27. Pieralli S, Kohal R, Jung R, Vach K, Spies B. 2017; Clinical outcomes of zirconia dental implants: a systematic review. J Dent Res.; 96:38-46.

28. Bremer F, Grade S, Kohorst P, Stiesch M.2011; In vivo biofilm formation on different dental ceramics. Quintessence Int .42:565-74.
29. Queiroz JR,Botelho MA, Sousa SA, Martinelli AE, Özcan M.2015; Evaluation of spatial and functional roughness parameters on air-abraded zirconia as a function of particle type and deposition pressure. J Adhes Dent .17(1):77-80. doi: 10.3290/j.jad.a33503.

30. Bae KH, Han JS, Seol YJ, Butz F, Caton J, Rhyu IC.2008; The biologic stability of alumina-zirconia implant abutments after 1 year of clinical service: a digital subtraction radiographic evaluation. Int $\mathrm{J}$ Periodontics Restorative Dent. 28:137-143.

31. Kollar A, Huber S, Mericske E, Mericske-Stern R. 2008; Zirconia for teeth and implants: a case series. Int J Periodontics Restorative Dent.28:479-487

32. Kerstein RB, Radke J.2008; A comparison of fabrication precision and mechanical reliability of 2 zirconia implant abutments. Int J Oral Maxillofac Implants. 23:1029- 1036. 